This item was submitted to Loughborough's Research Repository by the author.

Items in Figshare are protected by copyright, with all rights reserved, unless otherwise indicated.

\title{
Inter-agency governance risk in managing hospital responses to extreme weather events in New South Wales, Australia: a facilities management perspective of shared situational awareness
}

\section{PLEASE CITE THE PUBLISHED VERSION}

https://doi.org/10.1080/01446193.2013.853128

\section{PUBLISHER}

(c) Taylor \& Francis

\section{VERSION}

SMUR (Submitted Manuscript Under Review)

\section{PUBLISHER STATEMENT}

This work is made available according to the conditions of the Creative Commons Attribution-NonCommercialNoDerivatives 4.0 International (CC BY-NC-ND 4.0) licence. Full details of this licence are available at: https://creativecommons.org/licenses/by-nc-nd/4.0/

\section{LICENCE}

CC BY-NC-ND 4.0

\section{REPOSITORY RECORD}

Loosemore, Martin, Vivien W. Chow, and Tracie Harvison. 2019. "Inter-agency Governance Risk in Managing Hospital Responses to Extreme Weather Events in New South Wales, Australia: A Facilities Management Perspective of Shared Situational Awareness". figshare. https://hdl.handle.net/2134/26733. 


\section{Inter-agency governance risk in managing hospital responses to extreme weather events}

\section{Abstract}

Extreme weather is predicted to become more frequent and severe into the future. While our understanding of hospital infrastructure vulnerability to such events has advanced considerably in recent years, current approaches to healthcare facilities management treat hospitals in isolation from their surrounding governance infrastructure. However, recent research indicates that if hospital resilience is to be properly understood, health infrastructure must be managed holistically, as part of a much larger governance system of interdependent organisations. The inter-agency governance risks associated with this system are currently ignored in the facilities management literature. To explore these risks, an in-depth case study of twenty four agencies in the state of New South Wales, Australia is presented. The results show that facilities managers are embedded in a highly complex and dynamic array of governance boundaries which are largely unresolved and misunderstood. A number of practical strategies are presented which could be adopted to significantly improve facilities manager's integration into this system. These include: mapping hospital dependency on other agencies to build surge capacity; resolving overlapping operational boundaries with other agencies; pro-active risk reduction for critical external support infrastructure; understanding potential conflicts with the objectives external agencies in responding to an extreme weather event.

Keywords: Facilities management, hospitals, risk, inter-agency, governance, extreme weather events 


\section{Introduction}

Extreme weather events (EWEs) are defined as weather patterns that exceed a particular threshold and deviate significantly from mean climate conditions (Linnenluecke and Griffiths, 2010). Warnings that climate change is likely to lead to more frequent and intense EWEs are becoming increasingly frequent (see for example SSEFR 2011) and there is accumulating evidence that such events will test the limits of critical infrastructure and service resilience. Health infrastructure has been found to be especially vulnerable, with many recent examples of hospitals being overwhelmed, forced to close or having to evacuate their patients during an EWE (Carthey et al 2009, McGeorge et al 2011). Hughes and McMichael (2011:1) point out that such events present not only direct physical risks to health infrastructure but indirect risks arising from increased hospital admissions from vulnerable elements of the population such as the aged, chronically ill and clinically obese.

In investigating the vulnerability of health infrastructure to EWEs from a facilities management perspective, Loosemore et al (2012) used rich picture diagrams to demonstrate that hospital facilities cannot be treated in isolation from the wider systems in which they exist. To understand the full impact of an EWE, they must be seen as part of a much larger healthcare system. Loosemore et al's research supports the findings of Arboleda et al (2009) and PCI (2011) and showed that although the facilities management literature acknowledges that the health system is complex, it provides little insight into the interdependencies between critical health subsystems and of the 'cascading uncertainties' which can be produced when the system is under duress. It is clear that an understanding of how to create and manage resilient healthcare facilities depends, in part, on developing a conceptual understanding of 
the complex relationships between the various inter-organisational governance relationships within the healthcare system. This means considering relationships with emergency services such as the police; the army; the fire service; water, electricity and gas authorities and private providers; off-campus hospital suppliers; polyclinics; and aged care facilities. The interagency governance arrangements which determine how these external agencies interact with the hospital organisation and with each other is critical for a healthcare system to successfully respond to an EWE. Yet the issue of inter-agency governance has not been addressed in facilities management research. As Heng and Loosemore’s (2011) analysis of the brokerage role of health facilities managers found, gathering and channelling critical business information to support the facilities management function is difficult to achieve in practice, even within hospitals, let alone with external agencies. Heng and Loosemore (2011) found that the facilities management team is relatively disempowered in these wider organisational structures, which means that they are usually not in a position to demand that other business units share their information about facilities-related risks. For political and tactical reasons associated with exerting power over scarce and valuable space-related resources, many individuals with specialised knowledge and information about facilities risks are often unwilling to share it.

It is within this context that the aim of this paper is to explore the implications of interagency governance for the facilities management of public hospitals during EWEs. This will add an important inter-organisational dimension to the facilities management debate, which hitherto has been confined to intra-organisational issues. 


\section{Inter-agency responses to EWEs: moving from command-and-control to relational theories}

Inter-agency governance is defined as the processes involved in co-ordinating and controlling resources and actions of organisations, which are deployed to prevent and prepare for, combat, as well as recover from the impacts of an EWE (Ansell and Gash 2008). Research into the inter-agency responses to EWEs in which facilities managers are embedded has largely been informed by disaster management theory which has evolved to understand and manage such events. The earliest attempts to conceptualise this process can be traced back to Samuel Prince’s seminal work (Prince 1920) which derived a 'social theory' to explain human response to disaster. Building on this early work, research interest in collective community behaviour and organisational reactions to disasters flourished after World War II. This culminated in the work of Mileti and Drabek (1975) which synthesised a significant proportion of the early literature and created the concept of the Disaster Life Cycle which established the fundamental concepts of mitigation, preparedness, response and recovery used in most contemporary disaster management plans and facilities management litearture. Drabek (1986) refined this work and introduced the concepts of emergent behaviour and human systems in disaster response, igniting the current debate over the validity of the centralised or bureaucratic model promoted in disaster management.

Contemporary disaster management theory can be divided into two camps (Uhr 2009). The first is the 'traditional' perspective which has its origins in civil defence and classical organisational theory. This emphasises the importance of a centralised authority for a successful disaster response and the value of agreed, well-practiced operating procedures (Draber and McEntire 2002). The second, more contemporary view acknowledges emergent 
behaviours and is orientated towards decentralised or self-organising models operating on the basis of cooperation and collective problem solving (Mendonca et al. 2007). While these perspectives are different, underpinning both approaches, but yet missing from the facilities management literature, is agreement about the need to consider multi-agency governance during a disaster event to ensure inter-agency responses are coordinated. However, as highlighted by Quarantelli (1997), there is little consensus about what this actually means. Some view good inter-agency governance as simply informing other groups about what they will be doing, other see it as centralising decision-making within a particular agency or amongst a few key officials, while others see coordination as mutual agreements about how particular tasks should be carried out. This distinction is important from a facilities management perspective because in both models the facilities manager has to integrate themselves into the governance arrangements to ensure they are involved in and informed about the response strategy in advance and as it evolves.

Recent analysis of multi-agency responses to natural disasters (Houghton and Baber 2006; McMaster and Baber 2009) suggests that part of the difficulty managers face is that under normal operating conditions, emergency services practice what has been termed 'sequential single agency response'. This is where each service undertakes a discrete role and takes the lead role at different times in delivering services to the community. Typically, the procedures adopted by each agency have been optimised to respond to the most frequent scenarios they individually encounter. The 'boundaries' defining what each agency or emergency service will tackle are often standard operating procedures that are ingrained, linear and inflexible and which do not adequately consider the dynamic inter-agency interdependencies required to ensure an effective response to an EWE. However, in contrast to normal operating conditions, during an EWE event, multiple agencies are required to work on multiple tasks 
simultaneously, under time pressure and towards a common goal. This need for flexibility breaks traditional modes of operation and requires an element of adaptive capacity which is often missing from the multiple agencies involved in a response.

To avoid these problems, the field of disaster management has long advocated the value of building a common operational picture (COP) - a single representation of relevant multiagency response - to improve coordination between agencies. This has spurned a broad body of research into the value and use of Emergency Operation Centres (EOCs) adapted from the military with supportive research and development in ICT systems interoperability (Perry 1995). Post assessment of real-life responses to recent disasters demonstrates that the use of EOCs and their role in providing a COP improves the effectiveness of interagency responses (McEntire 2002; Department of Homeland Security 2012, Sommers 2009, Blanke and McGrady 2012). However, this research also suggests that simply sharing information and providing top-down coordination does not guarantee inter-agency coordination. So while the concept of COP remains relevant, emphasis has recently shifted from gathering and sharing information to consideration as to how it can be used to promote 'shared situational awareness’ (Endsley 1995; Wickens 2008). This most recent research has raised doubts about effectiveness of the traditional command and control model (Mendonca et al. 2007; Arslan et al. 2010). It is argued that while a central coordinating authority or control centre is of value in coordinating responses, imposing a hierarchical, military-type command structure is counterproductive if the desire is to encourage collaboration and cooperation between agencies. Secondly, reliance on rigid plans, decision protocols and standard operational procedures inhibits the opportunity for improvisation and adaption to novel conditions which typically arise during an EWE. In reality, the ability to develop an all-inclusive plan covering every eventuality is impossible, and an ability to adapt and improvise is an imperative. Most 
importantly, this research is also showing that even with an EOC and COP, inter-agency coordinating is highly dependent on pre-existing relationships between responding agencies established prior to the event (Danczyk 2007; Patton 2007; Ansell and Gash 2008; McMaster and Baber 2008; 2009, Department of Homeland Security 2012). Agencies that have regular contact and the opportunity to practice working together in disaster rehearsals and emergency drills develop greater situational awareness, can resolve potential conflicts in advance, develop higher levels of trust, work more collaboratively, and adapt more effectively to the dynamic challenges presented by events like EWEs (Uhr 2009).

\section{Method}

Regardless of the governance philosophy adopted, hospital facilities managers are required to manoeuvre within this inter-agency landscape and ensure that their interests in infrastructure resilience are represented in responding to an EWE. To investigate the challenges that hospital facilities management might face in managing within this network of interactions, we conducted an in depth analysis of one such system in the form of an instrumental case study of the complex inter-agency governance structure responsible for managing healthcare delivery in New South Wales, Australia. New South Wales (NSW) provides an ideal context in which to study interagency response to EWEs from a facilities management perspective. NSW is Australia's fifth biggest state with a population of about 7 million and an area of $801,428 \mathrm{~km}^{2}$. This area is bigger than California and New Mexico put together and about 3.25 times larger than the UK. NSW has suffered a number of extreme weather events in recent years, affecting more than 230 public hospitals which provide a wide range of services including emergency care, elective and emergency surgery, medical treatment, maternity services and rehabilitation programs. In addition to general admissions, many of these 
hospitals also offer day surgery and some services are delivered to local communities on an outpatient basis. The agencies that are involved in allowing this health system to function are listed in Table 1 under three sub-systems: NSW Health infrastructure; Emergency Services and; Critical Infrastructure.

\section{INSERT TABLE 1 HERE}

The agencies listed in Table 1 were the focus of our analysis which ensured that in addition to analysing the governance structures supporting the operation and maintenance of different types of health infrastructure in NSW, we also considered the emergency services and critical infrastructures that underpinned its operation. This allowed the various agencies with governance control or responsibility within and across the three sub-systems (NSW Health infrastructure, Emergency Services and Critical Infrastructure) to be compared; highlighting not only the potential conflicts and synergies within each sub-system, but also between them when required to work cooperatively in an EWE scenario.

The full complexity of this situation is illustrated in Table 2 which quantifies some of the response agencies in each of the categories in Table 1.

INSERT TABLE 2 HERE 
In terms of decision-making responsibility during an EWE, six aspects of governance control were analysed:

1. Healthcare service delivery

2. Operational planning (administrative control)

3. Asset management (physical infrastructure)

4. Land use, planning and building control (site and surrounding area)

5. Support services and procurement (purchase of services)

6. Funding and financial control

Data about these seven governance control arrangements was collected using various sources. These included: published governance structures for operating and maintaining public hospitals in New South Wales; hospital, agency and community disaster management plans; government policy and legislation; building control and standards guidance; published agency and government analysis of past EWE disaster responses; annual reports of responding agencies; government inquires in EWE responses; internal discussion papers and; disaster and emergency agency websites. This broad range of data was essential in identifying the complex intra-governance issues to explain how hospital facilities managers must interact with supporting emergency services (police, fire and rescue, ambulance and voluntary emergency services) and critical infrastructure (transport, public utilities and telecommunications) during normal and disaster conditions.

A single case study approach of NSW (albeit with multiple internal dimensions), like every approach, has well-recognised limitations, particularly around representativeness and generalizability. However, this approach enabled us to research this issue more intensively 
than we could have done across multiple case studies. As illustrated above, the number of potential agencies involved in the response to an EWE in our case study is very large, introducing complex and dynamic interdependencies which require an in-depth approach to properly understand. Furthermore, in response to the potential criticism that case study research findings are not generalisable, Flyvbjerg $(2011,310)$ argues that "while it is correct that the case study is a detailed examination of a single example, it is not true that a case study cannot provide reliable information about the broader class”. Indeed, Flyvberg (2011) argues that 'the force of example' is underestimated in organisational research and that when done well, contain no greater bias toward verification of the researcher's preconceived notions than other methods of inquiry. Indeed, according to Flyvberg, experience indicates that the case study contains a greater bias toward falsification of preconceived notions than toward verification. While the advantage of large samples is breadth and representativeness, the advantage of case studies is depth and validity.

\section{Results and discussion}

The discussion in this section focuses on the potential obstacles and opportunities presented by the current governance structures and approaches to inter-agency coordination to hospitals undertaking effective EWE management in our case study. To test the efficacy of current governance structures, two scenarios are analysed. The first scenario explores how hospital facility managers can support a community's response to an EWE. The second scenario explores how hospital facility managers can avoid its operations being disrupted and thereby itself becoming a casualty of an EWE. 
Scenario 1: Hospital infrastructure in supporting the community's response to EWEs

The complexity of inter-agency governance is illustrated by the following description of the range of agencies involved in planning for, responding to and recovering from an EWE response. In NSW, as in most parts of the world, responsibility for the formulation and maintenance of disaster plans is delegated to the lowest possible level, which in administrative terms is to local government, with a mechanism to elevate to higher order controls as necessary, at a district and even state-level. In total, 152 Local Governments exist across NSW and for the purposes of regional disaster management, Local Governments Areas (LGAs) have been grouped into 11 Emergency Management Districts. While whole-ofcommunity plans are formulated by Local Government for each of their areas and coordinated across the 11 Emergency Management Districts, responsibility for the health response as part of these plans occurs across a different set of operational boundaries, creating the risk that disaster planning for hospitals is undertaken in isolation from whole-ofcommunity disaster plans coordinated by Local Government officials. Under the provisions of the NSW Health Plan (NSW Health 2008), responsibility for disaster management for individual hospitals (both public and private) is allocated to 17 Local Health Districts (LHDs). This is done through Health Services Functional Area Coordinators (HSFAC) in each hospital. However, in terms of ensuring the ability to build adequate surge capacity within their hospitals, LHDs have limited influence over the centralised procurement from warehousing facilities supplying support services such as linen, catering, IT or consumable medical supplies within their districts. These components are controlled at a state-wide level by NSW Health. In the same way, during an EWE, LHDs will have little influence in mobilizing other agency resources. These types of inter-agency governance risks, caused by overlapping or misaligned operational boundaries are rarely highlighted or discussed and they 
significantly increase the likelihood that hospital facility managers will not be able to provide the health care support that the community requires and expects during an EWE. To address this gap in knowledge, Figure 1 summarises our analysis by abstracting the main factors faced by NSW hospitals in supporting a community’s EWE response effort. Figure 1 emerged from a mapping exercise which sought to map the physical infrastructure operated by NSW Health, various emergency response services and infrastructure support services around transport, telecommunications and utility supplies listed in Table 1.

\section{INSERT FIGURE 1 HERE}

Figure 1 shows that hospitals are fixed pieces of critical infrastructure, and like other respondent agencies, the organisation will deploy medical teams into the field as part of the EWE response, as well as receive in-bound casualties. Given that hospitals are not geared to provide their own disaster transport, they are highly dependent on other emergency service agencies to assist with the deployment of medical teams and supplies into the disaster field and also to transfer casualties from the field for treatment in hospital. Therefore the quality and timeliness of the 'health' response is dependent on the cooperation of other agencies. Our analysis indicated five critical issues that potentially impact a hospital facilities manager's ability to respond effectively to an EWE. These are: realistic estimates of surge capacity; time to prepare; dependency on other agencies to build surge capacity and to provide transport solutions; assumptions of access to and from the disaster field and; resolving overlapping or misaligned operational boundaries between other agencies. These are discussed in more detail below. 


\section{Realistic estimates of surge capacity}

Our analysis indicates that community disaster plans work on the assumption that hospitals will remain operational during an EWE and will have the capacity to expand and change their operating model and infrastructure to deal with an influx of causalities with abnormal healthcare requirements. Surge capacity is a recurrent problem in hospitals and while financial constraints are often blamed for this, other issues identified in post disaster reports include fragmented governance of surge resources, offsite storage of resources, over-loaded supply chains and poor communication about overflow management.

\section{Hospitals need time to prepare}

Hospitals need time to prepare, not only to deploy a response team, but also to be sufficiently resourced to receive mass casualties as well as to assist with the health response during the community’s recovery period. Post disaster reports show that a hospital's surge capacity will be dependent on the accessibility of additional staff and supplies. It will also depend on providing sufficient treatment space through a range of measures including cancelling elective surgery, diverting emergencies not related to the disaster to other hospitals and potentially transferring patients.

\section{Dependency on other agencies to build surge capacity}

All hospitals rely on other agencies to transport supplies and patients to and from site.

However, during an EWE, resources may be difficult to secure given most will be involved in preparing for deployment as part of the overall response or, depending on the nature of the EWE event, involved in the planned evacuation of the threatened community. 
Assumptions of access to and from the disaster field

There is an assumption that access to and from the disaster field will be possible during the course of a disaster response and recovery period. Not only does this assumption rely on surrounding infrastructure remaining operational (for example, roads, helipads or airports), it also relies on transport vehicles and equipment being capable of handing the conditions within the disaster field. As identified recently during severe floods in Australia and the UK, the inability of the available responders to negotiate flooded roadways or rough terrain significantly impacted the effectiveness of hospital responses.

\section{Overlapping or misaligned operational boundaries}

Impacting all three dependencies identified above is the potential overlap and/or misalignment of operational boundaries of the various responding agencies. Since EWEs typically affect a wide catchment area, they are likely to be covered by more than one local disaster plan, and potentially even some regional or district-based disaster plans. This requires hospitals to be familiar with the procedures and arrangements contained within multiple disaster plans, and also to build operational relationships with a wide range of stakeholders and responding agencies.

In each of these areas, our analysis revealed a range of enablers and barriers to effective interagency response to EWEs and these are presented in Table 3. 
Scenario 2: Hospital site becoming part of the disaster zone

Figure 2 summarises our analysis of this scenario by abstracting the situation faced by hospitals in avoiding becoming a casualty during an EWE.

\section{INSERT FIGURE 2 HERE}

Figure 2 and our analysis of past disaster response reports indicated five critical issues that potentially impact a hospital's performance in response to an EWE: funding of asset development; coordinating with agencies external to the health system and; potential conflicts between external agencies. These are discussed in more detail below.

\section{Funding of asset development}

In Australia, the state government will typically own a hospital's physical assets including the site, and through its various agencies, oversee and fund its upgrade or renewal. Individual hospital facilities managers and regional health boards tend to have funding and delegated responsibility to manage the operation including routine maintenance of individual sites and supporting built infrastructure. On face value this split in agency responsibility appears innocuous. However, under this arrangement, individual hospital facilities managers have limited influence over decisions to upgrade or renew their hospital's site or its built assets. Within the ranks of state government itself, the division of responsibility between departments is equally important. While the relevant state or national health department may have responsibility for setting priorities for capital works (renewal or upgrade) across the portfolio supporting the public health system, state treasuries will ultimately dictate the health budget and health departments must compete with other demands for public funding. A 
second issue is that at a state level, decisions regarding capital expenditure on the upgrade or renewal of assets within an individual site are typically prioritised, with reference to the entire hospital portfolio. What may be of high priority to an individual hospital in its disaster planning may not necessarily be considered so by government at the state level.

Coordination with agencies external to the health system

As discussed above, during an EWE, hospitals often rely on interactions with agencies outside the health sector, with whom they do not have routine contact. Although most health systems attempt to ensure independence through the provision of backup sources such as the installation of generators, it does not necessarily reduce the reliance on other agencies to assist. For example, as illustrated during a recent heatwave in Australia, back-up generators can fail, requiring emergency support from external services during the outage period. The global trend towards privatisation of public utilities (power, gas, water supply and telecommunication) has introduced an increased level of complexity into coordinating these types of critical dependencies.

\section{Potential conflict between external agencies and hospital objectives}

One major problem for a facilities manager in dealing with an EWE is that external agencies may have conflicting objectives to those of the hospital. For example, local aged care facilities often lack a disaster plan and tend to evacuate their patients and residents to tertiary hospitals during an event such as a flood, to prevent them being cut-off. Not only could patients become stranded en-route, but the arrival of many new vulnerable old people into a hospital at a time when it is already under stress puts undue strain on the response effort. Similarly, in a heat wave, electricity providers experiencing a surge in electricity demand from the community might have to ration electricity supply to prevent disastrous outages. 
This may result in the cancellation of non-critical health services to the community until the heat wave has passed.

In each of the above areas our analysis revealed a range of enablers and barriers to effective inter-agency response to EWEs under this scenario are presented in Table 4.

\section{INSERT TABLE 4 HERE}

\section{Conclusions}

The aim of this paper was to explore the implications of inter-agency governance for the facilities management of public hospitals during EWEs. It was argued that past research on facilities management governance issues has taken an intra-department focus and there is a need to balance this with inter-organisational insights. By studying these issues under two distinct scenarios within an in-depth single case study of NSW Australia, this paper has illustrated how both scenarios present different sets of issues which impact on a hospital's performance during an EWE and therefore warrant separate attention and planning as part of facilities manager's disaster management responsibilities. What is evident is that in responding effectively to an EWE the management of hospital facilities cannot be seen in isolation from the wider management of the disaster and emergency management system. It is also clear that facility managers cannot effectively play a role in maintaining healthcare to the community during an EWE if they fail to build, nurture and understanding their relationships with other agencies involved in a disaster response. This needs to happen before, during and after every event. These external relationships are critical in facilities managers understanding and planning how the hospital facility will provide adequate and appropriate treatment space to cope with a surge and change in patient demand profiles, additional staff 
and how it will access and manage sufficient medical and other resources to do so.

Furthermore, access to and from the hospital during the course of the disaster response and recovery period is critical and depends on surrounding infrastructure remaining operational and on sufficient transport and equipment being available. Impacting on all these requirements is the potential overlap and/or misalignment of operational boundaries of the various responding agencies, requiring hospital facility managers to be familiar with the procedures and arrangements contained within multiple disaster plans, and also to build operational relationships with a wide range of stakeholders and responding agencies and understand any conflicting objectives which may affect a hospital's operational capacity. While the limitations of this research is that it was based on one case study of NSW, and while further research is clearly needed into the inter-agency challenges of the facilities management function, its value is that it reveals for the first time, a set of issues and skills which are not typically covered in facilities management research literature. In particular, it highlights the importance of: adopting a systems perspective in understanding the health system as a whole; understanding the power, politics and economics of governance; stakeholder management; inter-agency relationship building and; of understanding the objectives, plans and constraints of other organisational functions (external and internal) which the facilities manager depends on. 


\section{References}

Ansell, C. and A. Gash (2008). Collaborative Governance in Theory and Practice, Journal of Public Administration Theory and Research 18(4): 543- 571.

Arboleda, C.A., Abraham, D.M., Richard, J.-P.P. and Lubitz, R. (2009) Vulnerability assessment of health care facilities during disaster events, Journal of Infrastructure Systems, 15(3), 149-61.

Blanke, S. and E. McGrady (2012) From Hot Ashes to a Cool Recovery: Reducing risk by action on business continuity and disaster recovery lessons learned, Home Healthcare management Practice 24: 73 - 80.

Carthey, J., Loosemore, M., and Chandra, V. (2009) “Adapting Australian health facilities to cope with climate-related extreme weather events “, Journal of Facilities Management, 7:1, pp.36 - 51 .

Danczyk (2007). Intergovernmental Interaction in threat Preparedness and Response California's Approach. 9th National Public Management Research Conference, Oct 25 - 27. University of Arizonia, Tuscon.

Department of Homeland Security (2012). 2012 The State of FEMA. Leaning Forward: Go Big, Go Early, Go Fast, Be Smart. Washington DC.

Drabek, T. (1986). Human Systems Responses to Disaster: An Inventory of Sociological Findings. US, Springer-Veriag, NY. 
Draber, T. and D. McEntire (2002) Emergent Phenomena and Multi-Organisational

Coordination in Disasters: Lessons from the Research Literature, International Journal of Mass Emergencies and Disasters, 20(2): 197 - 224.

Endsley, M. (1995). "Towards a Theory of Situational Awareness in Dynamic Systems, Human Factors, 37: 32-64.

Fischer, H. I. (1998) Response to Disasters: Facts verses Fiction and its Perpetuation: The Sociology of Disaster, 2nd Edition. Maryland, University Press of America.

Flyvbjerg, B, (2011) Case Study," in Norman K. Denzin and Yvonna S. Lincoln, eds., The Sage Handbook of Qualitative Research, 4th Edition, Thousand Oaks, CA: Sage, pp. 301316.

Heng, H.K.S. and Loosemore, M. (2011) Structural holes in hospital organisations: exploring the brokerage potential of facilities managers from a social network perspective, in Egbu, C. and Lou, E.C.W. (eds) Procs $27^{\text {th }}$ Annual ARCOM Conference, Bristol, UK, 5-7 September, ARCOM, Reading, pp. 515-24.

Houghton, R., C. Baber, et al. (2006) Control in Emergency Services Operations: A Social Network Analysis, Ergonomics 49(12-13): 1204 - 1225. 
Hughes, L and McMichael T (2011) The critical decade: climate change and health, Climate Change Commission, Department of Climate change and energy efficiency, Commonwealth of Australia, Canberra, Australia

Kapucu, N., T. Arslan, et al. (2010) Collaborative Emergency Management and National Emergency Management Network, Disaster Prevent \& Management 19(4): 452 - 468.

Linnenluecke, M. \& Griffiths, A. (2010). Beyond adaptation: resilience for business in light of climate change and weather extremes. Business \& Society, 49, 477.

Loosemore, Martin, Vivien W Chow and Denny McGeorge (2012) Modelling the risks of extreme weather events to Australasian hospital infrastructure using rich picture diagrams. Construction Management and Economics. 30 (12) 1071-1086

McEntire, D. (2002) Coordinating multi-organisational responses to disasters: Lessons from the March 28, 2000 Fort Worth Tornado, Disaster Prevention and Management 11(5): 369 379.

McGeorge, D, Chow, V. W., Carthey, J \& Loosemore, M. (2011). Modelling the impact of extreme weather events on healthcare infrastructure using rich picture diagrams. In: Egbu, C. \& Lou, E. C. W. (eds.) Procs 27th Annual ARCOM Conference, 5-7 September 2011, Bristol, UK. Association of Researchers in Construction Management, 973-981.

McMaster, R. and C. Baber (2008). Multi-Agency Operations: Cooperation during Flooding. Birmingham, Human Factors Integration Defence Technology Centre as part of the UK Ministry of Defence Scientific Research Programme. 
McMaster, R. and C. Baber (2009). Common Operating Pictures and their potential for Multi-Agency Work. Birmingham, human factors integration design technology centre, UK minister of defence scientific research programme.

Mendonca, D., T. et al. (2007). "Collaborative adhocracies and mix-and-match technologies in emergency management. Using the emergent interoperability approach to address unanticipated contingencies during emergency responses." Communications of the ACM 50(3): 45 - 49.

Mileti, D., T. Drabek, et al. (1975). Human Systems in Extreme Environmental: A Sociological Perspective. Boulder, Institution of Behavioural Science, Monograph 2.

NSW Health (2008). NSW HEALTHPLAN: A supporting Plan of the New South Wales State Disaster Plan (DISPLAN). N. A. S. Counter Disaster Unit. Sydney, NSW Government Printer.

Patton, A. (2007). Collaborative Emergency Management. Emergency Management. Washington, DC, ICMA: 71 - 85.

Perry, R. (1995) The Structure and Function of Community Emergency Operations Centres, Disaster Prevention and Management, 4 (5): 37 - 41.

Prince, S. (1920) Catastrophe and Social Change, New York, Green \& Co. 
Productivity Commission (2011) Barriers to effective climate change adaptation.

Productivity Commission Issues Paper, October, Commonwealth Government of Australia.

Quanantelli, E. (1997) Ten Criteria for Evaluating the Management of Community Diasters, Disasters, 21(1): 39 - 56.

Sommers, S. (2009) Measuring Resilience Potential: A adaptive strategy for organisations crisis planning." Journal of Crisis Management 17: 12-23.

SSEFR (2011) Climate resilient infrastructure: preparing for a changing climate, Secteratry of state for environment, food and rural affairs, H M Government, HMSO, London UK

Uhr, C. (2009). Multi-Organisation Emergency Response Management: A Framework for Further Development. Department of Fire Safety Engineering and Systems Safety. Lund, Sweden, Lund University. Doctoral Thesis.

Wickens, C. (2008) Situational Awareness: Review of Mica Endsley's 1995 Articiles on Situational Awareness Theory and Measurement, Human Factors, 50(3): 397 - 403. 


\section{TABLES}

Table 1: Agencies involved in delivery of NSW healthcare

\begin{tabular}{|c|c|c|}
\hline $\begin{array}{l}\text { NSW Health } \\
\text { Infrastructure }\end{array}$ & $\begin{array}{l}\text { NSW Emergency } \\
\text { Services }\end{array}$ & $\begin{array}{l}\text { Critical Infrastructure } \\
\text { (Transport, Pubic Utilities, Telecommunications) }\end{array}$ \\
\hline - Public Hospitals & - NSW Ambulance & - National Road Network \\
\hline - Private Hospitals & Service & - State Roads \\
\hline - Primary Health & - NSW Police Force & - Local Roads \\
\hline Care Providers & - NSW State Fire and & - National Interstate Rail Networks \\
\hline - Aged Care & Rescue Service & - Metropolitan \& State Rail Network \\
\hline \multirow[t]{13}{*}{ Providers } & - Volunteer Rural Fire & - Public / Community bus Networks \\
\hline & Services & - Airports \\
\hline & - Volunteer & - Power Generation \\
\hline & Ambulance Officers & - High Voltage Electricity Supply / Distribution \\
\hline & - State Emergency & Network \\
\hline & Services & - Electricity Supply Distribution to Sites including \\
\hline & & Street Lighting \\
\hline & & - Gas Supply Network \\
\hline & & - Potable Water \& Sewage Supply - Bulk Supply \\
\hline & & - Potable Water \& Sewage Distribution Networks \\
\hline & & and Infrastructure (Local) \\
\hline & & - Voice and Data Communications - Network \\
\hline & & Infrastructures / Licensed Carriers. \\
\hline
\end{tabular}


Table 2: Response agencies and operational districts contributing to an EWE response in NSW.

\begin{tabular}{ll}
\hline Response Agencies & Operational Divisions or Regions across NSW \\
NSW Local Governments & 152 LGA across NSW \\
Public Hospitals (receiving hospitals) & 17 Local Health Districts \\
Ambulance Service & 226 Ambulance Stations; 5 Regional Control Centres \\
Police Service & 80 Local Area Commands, 6 Regional Commands \\
Fire \& Rescue Service NSW & 338 Stations; 4 Regional Commands \\
Volunteer Rural Fire Service & 16 Districts; 4 Regional Commands \\
State Emergency Services & 228 Units; 17 Regions based on River Catchments \\
& \\
\hline Critical Infrastructures & Stakeholders / Operational Licences across NSW \\
Electrical & Transgid + 3 HV Distributors \& 12 Retail Licences. \\
Gas Supply ` & 12 Licensed Network Operators \\
Water & 2 Bulk Suppliers, 2 Metropolitan \& 105 Rural Water Utilities \\
Communications (voice \& data) & 189 Active Licensed Carriers (321 licences issued in total) \\
\hline
\end{tabular}


Table 3 Inter-agency enablers and barriers to hospital EWE response

Critical issues

Realistic estimates of surge

capacity.

\section{Enablers}

Ensuring that assumptions on

which surge capacity has been

estimated are articulated and fully

understood both within the Health

System and agencies responsible

for coordinating the whole-of-

community response.

Estimates of surge capacity need to

include inter-dependencies such as

capacity of secondary receiving

facilities, as well as any demands

drawn on central supplies and pool

of rostered staff.

\section{Barriers}

Split in decision-making

responsibility between agencies

controlling resources essential in

building a hospital's surge

capacity.

Just-in-time inventory systems

providing minimum on-site

storage.

All hospitals rely on the same

shared centralized warehousing

facilities and suppliers.

Restructuring has led to steady decline in health-care worker to patient ratios and many staff are rostered.

Surge capacity relies on ability to transfer patients to other facilities which have the same expectation. 


\begin{tabular}{|c|c|c|}
\hline & interdependencies on other & sector will rarely be responsible for \\
\hline & agency’s resources to build their & activating a disaster plan (possible \\
\hline & surge capacity i.e. transport, draw & exception being the threat of a \\
\hline & on central supplies, staffing pool \& & disease epidemic) and therefore \\
\hline & secondary receiving hospitals. & will be reliant on others to provide \\
\hline & & sufficient warning. \\
\hline & Accelerating the amount of early & \\
\hline & warning given to hospitals by & Risk in hospitals over-reacting \\
\hline & identifying and agreeing what & resulting in potentially costly \\
\hline & 'triggers' hospitals to initiate alert & preparation that may not be \\
\hline & status. & necessary or taking action that is \\
\hline & & uncoordinated with whole-of- \\
\hline & & community COMMAND AND \\
\hline & & CONTROL efforts. \\
\hline Dependency on other agencies to & Opportunity for hospitals / health & Competing demand placed on \\
\hline build surge capacity \& to provide & systems to pre-contract resources & resources prior and during a \\
\hline transport solutions. & from other agencies in preparation & disaster. \\
\hline & for a disaster scenario and for these & \\
\hline & arrangements to be identified and & \\
\hline & well-articulated within disaster & \\
\hline & plans. & \\
\hline
\end{tabular}

Assumptions of access to and from Assumptions regarding transferring the disaster field existing patients to receiving

Hospital administration may have little influence over the activities or hospitals or alternative facilities, allocation of resource of agencies need to be identified and well- $\quad$ providing them with a transport articulated within disaster plans. solution. 
solution may themselves be

impacted by the disaster.

Overlapping or misaligned operational boundaries
Where feasible, align day-to-day

operational boundaries of response

agencies with those adopted for

disaster management purposes.

Hospital administrations need to

identify which local and district

plans they have been included

within and become familiar with

the command and control

structures in-place for each.
Those responsible for the

formulation of whole-of-

community response need to be aware of the call on a hospital's resources by other local or district plans. 
Table 4: Summary of issues identified impacting disaster planning preventing a hospital from becoming a casualty during a disaster

Critical issues

Funding of asset development
Enablers

Hospital administrations are in the

best position to evaluate the

vulnerabilities of their site and

infrastructure, and the resourcing

priorities needed to prevent a

hospital becoming a causality of a

disaster.

Capacity building in terms of

education, skills and resources

should be directed to the

development of strategies aimed at

mitigating the impacts of natural

disasters on public hospitals.

Site and building adaption aimed at mitigating the impacts of a disaster need to self-deploy or be able to be activated by hospital staff.

Hospital administrations in co-

operation and agreement with other

\section{Barriers}

Hospital administrations generally

have little influence in decisions

regarding the prioritisation or

allocation of resources supporting

the renewal or upgrade of hospital

sites or buildings.

Many hospitals are not resourced and staffed to defend their site or

built infrastructure against impacts

of a weather-induced disaster and

are therefore reliant on the

assistance of other agencies when

sites come under direct or indirect

threat.

The decision to abandon a hospital

site and evacuate staff and patients

will be made by command and

control for the whole-of-

community response rather than

the Hospital Administration or 


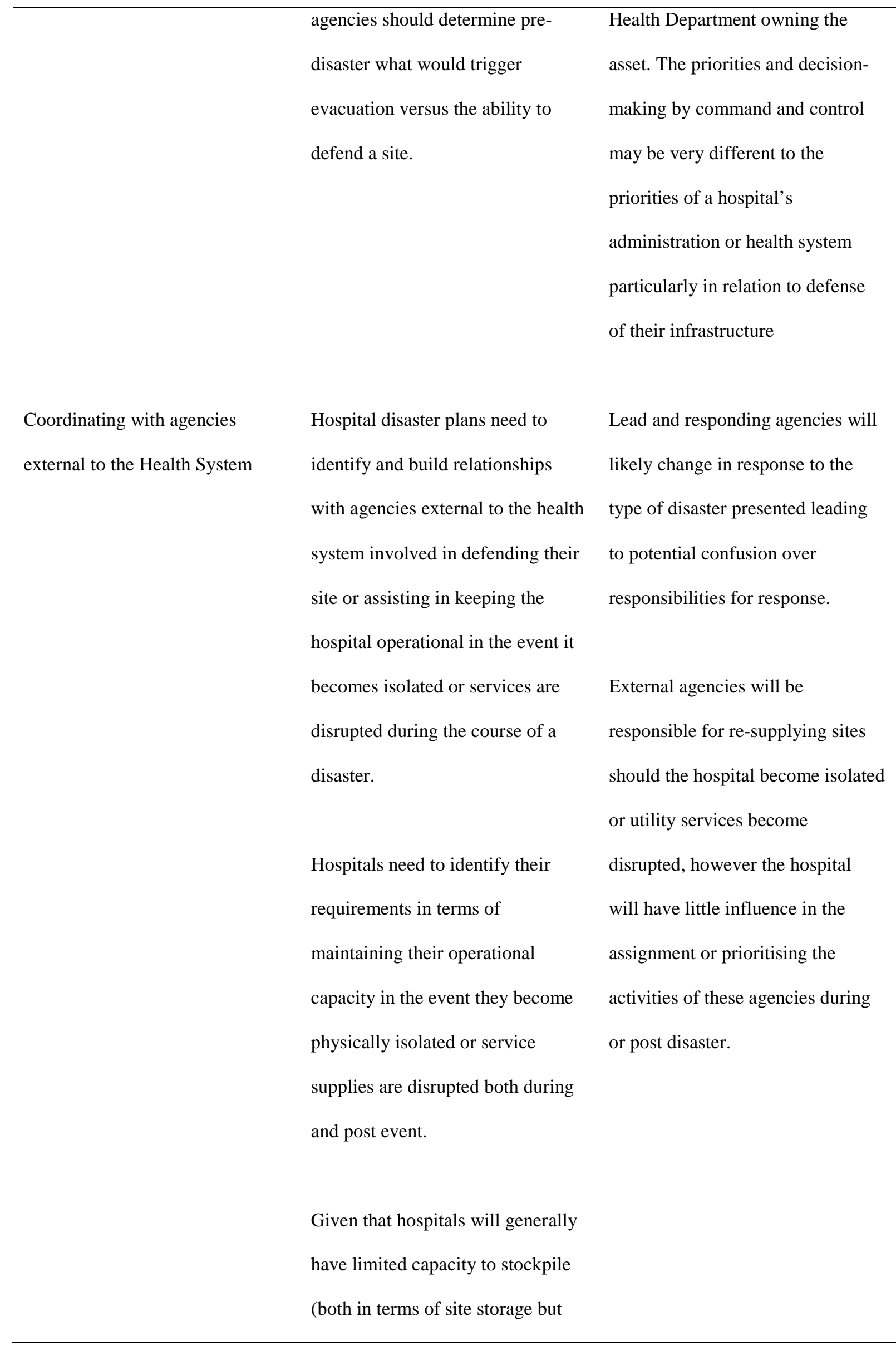


also having the time to source or

gather additional supplies), plans

need to incorporate strategies

allowing sites to be re-supplied and

for staff to be relieved.

Potential conflicts between

external agencies
Hospital administrations in cooperation and agreement with other agencies should determine predisaster at what point priority for resources and access needs to switch from supporting the response effort to defending the hospital site and infrastructure from becoming causality.
The decision to defend a hospital site and the allocation of resources for this task will be made by command and control for the whole-of-community response rather than the hospital administration or Health Department owning the asset. The priorities and decision-making by command and control may differ to those of the hospital's administration or health system and therefore if such 'triggers' are not agreed to pre-disaster, could result in conflict compromising timely action from being taken. 


\section{FIGURES}

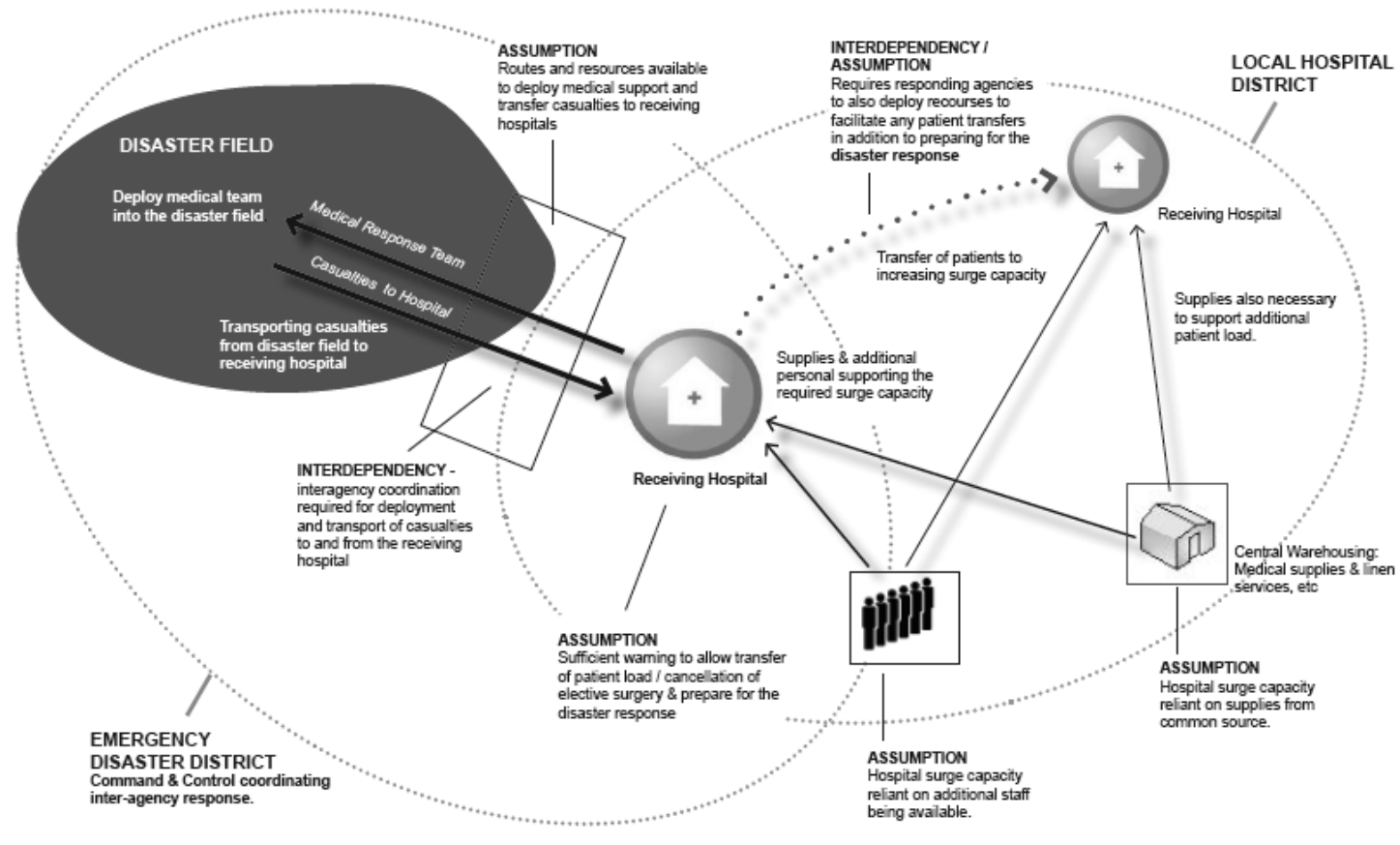

Figure 1: Scenario 1 - hospitals supporting the community response 


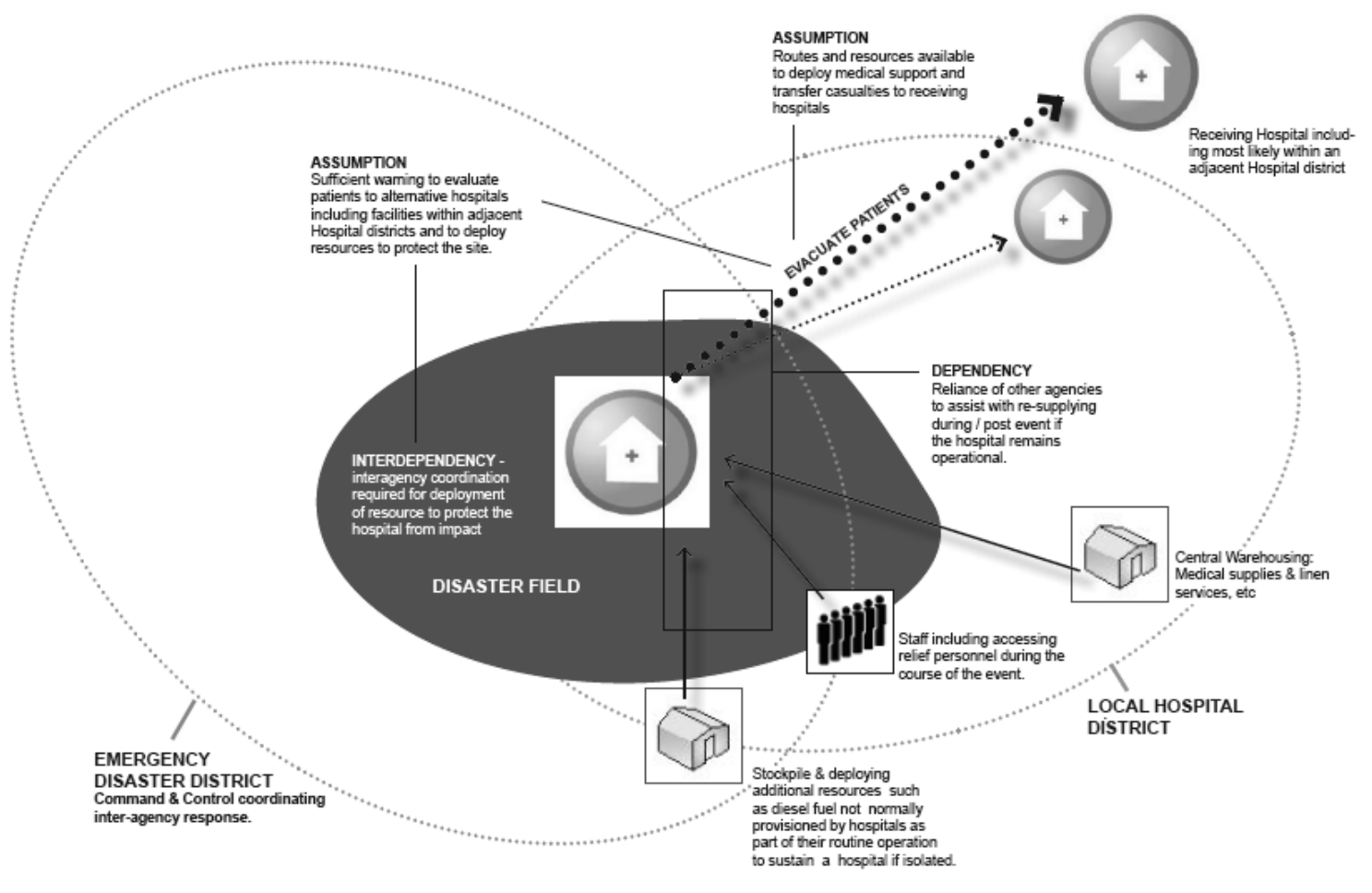

Figure 2: Scenario 2 - conditions needed to avoid the hospital being a casualty of the disaster 